Res Publica. Revista de Historia de las Ideas Políticas ISSN-e: 1989-6115

\title{
La referencia a América como evidencia del "estado de naturaleza" en las teorías contractuales clásicas
}

\author{
Manuel Romero*
}

Recibido: 21 de agosto de 2018 / Aceptado: 10 de junio de 2019

Resumen. La problemática de apropiar a América en el pensamiento occidental incentivó una producción conceptual que reconfiguró la forma de entender la política y el poder. En este contexto de reordenamiento del cosmos europeo, surgiría una teoría que permitirá interiorizar al Nuevo Mundo en el imaginario político de occidente: el contractualismo. Los principales autores de esta corriente serán Hobbes, Locke y Rousseau. El recorrido teórico que refieren éstos es similar: los hombres viven en una etapa pre-social llamada estado de naturaleza, que es superada al desarrollar un pacto social, que permite ir conformando un estado social. Se concluye que América será una pieza central en el esquema contractual, principalmente porque su referencia proveerá de un sustento empírico a los hipotéticos que se enarbolarán sobre dicho esquema.

Palabras clave: América; contractualismo; estado de naturaleza; derecho natural.

\section{[en] The Reference to America as Evidence of the "State of Nature" in Classical Contractual Theories}

\begin{abstract}
The problem of appropriating America in Western thought encourages a conceptual production that reconfigured the way of understanding politics and power. In this context, a theory would arise that would allow internalizing the New World in the European political imaginary: contractualism. The main authors of this current will be: Hobbes, Locke and Rousseau. The theoretical course that these refer to is similar: men live in a pre-social stage called the state of nature, which is overcome when developing a social pact, which allows for the formation of a social state. It is concluded that America will be a central piece in the contractual scheme, mainly because its reference will provide an empirical support to the hypotheticals that will be raised in said scheme.
\end{abstract}

Keywords: America; Contractualism; State of Nature; Natural Right.

Sumario: Introducción. 1. La emergencia de los contractualismos: antecedentes generales. 1.1. La tradición clásica del derecho natural. 1.2. La tradición moderna del derecho natural. 1.2.1. Los contractualismos. 2. Visiones de América y diferencias en los contractualismos. 2.1. El contractualismo de Hobbes. 2.1.1. América como el punto de proyección del contractualismo de Hobbes. 2.2. El contractualismo de Locke. 2.2.1. América como el punto de proyección del contractualismo de Locke. 2.3. El contractualismo de Rousseau. 2.3.1. América como el punto de proyección del contractualismo de Rousseau. 3. Conclusiones.

Cómo citar: Romero, M. (2019). La referencia a América como evidencia del "estado de naturaleza" en las teorías contractuales clásicas, en Res Publica 22.2, 349-363.

\footnotetext{
Universidad de Chile manuel.romero@ug.uchile.cl
} 
El descubrimiento o redescubrimiento de América por parte de Colón supuso un desafío cognoscitivo para el europeo; esto, principalmente, porque aquel Nuevo Mundo hallado de forma "accidental" estaba al margen de todos aquellos imaginarios, ideas y paradigmas desarrollados para ese entonces por occidente. Ante la necesidad de situar a América dentro de un esquema de significación que permitiese reconocer y asumir la existencia de este continente en el pensamiento occidental, progresivamente el europeo irá desarrollando nuevas abstracciones, ideas y relatos que ayudarán en la tarea de reordenar el antiguo cosmos sacudido por la novedad americana.

El primer paso en la internalización cognoscitiva de América se daría en el año 1507. Durante ese lustro el cartógrafo alemán Martín Waldseemüller presentará un planisferio llamado Universalis Cosmographia. Esta obra será la primera en la que se represente a América como un continente nuevo y diferente de Asia, por lo que tendrá mucha importancia en términos geopolíticos - después de esta carta, la racionalización del mundo se sitúa desde otra perspectiva para el europeo ${ }^{1}$ - . Posteriormente al reconocimiento y el bautismo geográfico en el "mapa-mundi" del continente americano, el centro de atención se desplazó desde la categorización cartográfica a otros aspectos de tipo racionalista y humanista - ¿qué es América?, y, ¿qué es el otro? - típica de la época renacentista que se inaugura. A partir de entonces, una gran cantidad de autores intentarán definir, categorizar e interiorizar a América en el saber occidental.

En el contexto del trabajo de "internalización”, el europeo desarrollará novedosas abstracciones que le permitirán situar a América desde un nuevo esquema de orden. Términos como los de Nuevo mundo o Buen salvaje, por ejemplo, serán una muestra de aquella original producción conceptual. Pero, además de estimular lo americano a la producción de términos analíticos inéditos, también su encuentro incentivará la realización de nuevas lecturas sobre antiguos conceptos que habían caído en desuso, este es el caso de los términos de estado de naturaleza, pacto social y estado social ${ }^{2}$, que para la época moderna volverían a retomar notoriedad. Es precisamente desde estos últimos conceptos mencionados que se sostendrá la llamada teoría contractualista clásica. Ésta se daría como consecuencia de un cambio en la percepción de la sociedad respecto de las fuentes del poder y su naturaleza. Los principales autores de esta propuesta serán Hobbes, Locke y Rousseau. La relación conceptual que refieren éstos es similar: los hombres en un periodo antecedente a las instituciones, viven en una etapa pre-social llamada estado de naturaleza, etapa que es superada al desarrollar un pacto social, pacto que a su vez permite conformar un estado social.

En lo que a ámbitos de fundamentación del poder político se refiere, la teoría contractual representará un giro copernicano en el pensamiento, esto, porque será la primera teoría política que justificará la soberanía de forma secular — hasta antes de Hobbes, que fue el primero en desarrollar una propuesta contractual plenamente elaborada $^{3}$, el poder se justificaba de manera natural o apelando a que la soberanía

J. Hessler, The naming of America. Martin Walseemüller's 1507 World Map and the Cosmographiae Introductio, London, D Giles Limited/Library of Congress, 2008, pp. 5 ss.

2 Ya desde tiempos de Platón y los sofistas que es observable el uso de algunos de estos términos, aunque con cargas significativas distintas de las que se le dan para la modernidad.

3 Si bien el desarrollo de la teoría contractual puede verse en pensadores modernos anteriores a Hobbes, como es el caso de Hugo Grocio, solo desde el trabajo del autor del Leviatán que la propuesta contractual se presentaría de una manera plenamente secular y clara - Grocio en su propuesta contractual, mezcla indistintamente elementos del derecho natural, preceptos de derecho divino positivo y normas consuetudinarias del derecho 
venía por derecho divino-, por lo que esta visión legitimadora de la autoridad contractualismo- es enteramente original y revolucionaria. Cabe entonces preguntarse: ¿cómo surge y qué refiere?, y, considerando que es una teoría del poder que se da post-encuentro del nuevo mundo, si acaso América, ¿habría incidido de alguna manera en la articulación y configuración de las teorías contractuales?

Creemos al respecto, que América será una pieza central en la teoría contractualista, principalmente, porque su referencia proveerá de un sustento empírico a los hipotéticos que se enarbolarán en dicho esquema - para todos los autores contractuales el nuevo mundo es el ejemplo del estado de naturaleza, de aquélla caótica condición pre-social de la cual se hizo necesario salir mediante la creación de instituciones-.

Para ahondar en lo reseñado, el artículo se dividirá en tres apartados: en el primero - esto en función de situar filosófica y contextualmente la emergencia de los contractualismos-, se lleva a cabo una breve revisión de los cambios que se han suscitado sobre las nociones del derecho natural; en la segunda sección, se analizará en profundidad el pensamiento de los autores contractuales, categorizando en forma general sus teorías y reflexionando acerca de la influencia que tuvo América en la conformación de sus propuestas; para, finalmente, en un tercer apartado, proponer las conclusiones del trabajo.

\section{La emergencia de los contractualismos: antecedentes generales}

Antes de abordar los contractualismos y analizar en detalle la incidencia que tuvo América en la elaboración de éstos, creemos conveniente reseñar el recorrido teórico que transcurrió desde las concepciones del derecho natural clásico al moderno. Este breve recorrido lo hacemos para situar epistémicamente a la teoría contractual, la cual es articulada y constituida desde las nociones modernas del derecho natural.

\subsection{La tradición clásica del derecho natural}

La tradición filosófica y jurídica clásica del derecho natural ${ }^{4}$ imperó por más de veinte siglos en Occidente. Sus orígenes se remontan a la época arcaica de Grecia, pero no sería hasta llegar a Aristóteles donde esta tradición alcanzaría un desarrollo más elaborado. Para Aristóteles, el Estado es una creación que se da producto del impulso natural humano a lo social, o dicho de otro modo, la estructura jurídica de la sociedad — gobierno de unos hombres sobre otros y cuerpo de normas y mandatos positivos - se dan merced de las disposiciones de carácter natural ${ }^{5}$. Con posterioridad al estagirita, las doctrinas aristotélicas del derecho natural serían retomadas por los juristas romanos y regimentadas en su derecho. Las invasiones bárbaras a Roma

de gentes - E. Rommel, Derecho natural: Historia-doctrina, México D.F., Editorial Jus, 1950, pp. 67-70; J. Hervada, Síntesis de historia de la ciencia del derecho natural, Pamplona, Eunsa, 2007, pp. 87-88.

$4 \quad$ La tradición del derecho natural es una doctrina filosófica y del derecho a través de la cual se considera que las normas o derechos vienen supeditados desde la naturaleza propia del ser humano y son anteriores a cualquier derecho establecido. Para la tradición clásica, el derecho natural es derecho vigente y, por consiguiente, derecho real. J. Hervada, op. cit., pp. 20-22.

5 Aristóteles, Politica, Madrid, Gredos, 1988. 
y la decadencia que llevaron éstas al imperio, hicieron que la tradición del derecho natural viviera un par de siglos de abandono, esto, hasta nuevamente ser retomada con fuerzas a partir del siglo XI. Desde esas fechas, el derecho natural sería reinterpretado y comenzaría a ser leído en clave cristiana ${ }^{6}$.

\subsection{La tradición moderna del derecho natural}

Desde el siglo XVI, una serie de eventos históricos como del pensamiento comenzarán a mancillar progresivamente las concepciones clásicas del derecho natural. Entre los acontecimientos que fueron transformando las formas en que se entendía el derecho y el poder, destacamos: (1) el desarrollo del renacimiento y el humanismo, estos procesos llevaron a poner en el centro de las preocupaciones reflexivas los aspectos terrenales-humanos, en desmedro de los temas teológicos-suprasensibles; (2) la dolorosa experiencia de las guerras religiosas posteriores a la reforma protestante, que condujo a muchos espíritus a la búsqueda de principios comunes a todos los hombres, principios independientes de alguna fe religiosa en los que se pudiesen hallar las bases para el entendimiento pacífico ${ }^{7}$; (3) El auge del racionalismo, que postulaba la autonomía del saber racional frente a los datos de la fe religiosa y el saber teológico; (4) el auge de la navegación y el comercio, que dio pie al desarrollo del derecho internacional; (5) el descubrimiento y colonización de América, que, por un lado, supuso un replanteamiento del pensamiento occidental; y que, por otro lado, abonó al escepticismo filosófico sobre la "naturalidad" de la civilización y la idea de absolutos morales, nociones que pregonaba la tradición aristotélico-tomista.

La voluntad de resolver los problemas jurídicos y culturales que suscitaron estos acontecimientos derivó en un esfuerzo que iría alejando, casi sin pretenderlo, las concepciones del derecho natural clásicas hacia nuevas formas de entender la soberanía y el poder. Sin embargo, el tránsito desde la doctrina naturalista clásica a la que ha pasado a denominarse como doctrina moderna del derecho natural no fue brusco. Se trata más bien de un proceso que mantuvo ciertas líneas de continuidad. Hay una ruptura, pero esta fue lenta y no abrupta ${ }^{8}$. El rasgo distintivo clave del proceso puede situarse en el cambio de la concepción trascendente del derecho natural hacia una concepción inmanente, o dicho en otras palabras, desde una concepción de derecho natural que ya no depende ni se interpreta desde el derecho divino - hay una separación de la "ley eterna" divina de la ley natural, la moralidad y el derecho9-. Es difícil encontrar una explicación global y unívoca de esta transición. El hecho cierto es que las teorías del derecho natural, desde por lo menos la segunda mitad del siglo XVII en adelante, estarían ya enmarcadas según las posiciones de la corriente denominada como Escuela moderna del Derecho Natural ${ }^{10}$ (EMDN).

6 Para los juristas y filósofos del derecho cristiano, el derecho natural se funda en último término en el derecho divino, o en otras palabras, la ley natural se constituye desde la "ley eterna" de dios.

J. Hervada, op. cit., p. 44.

Ibidem, p. 56.

E. Rommel, op. cit.

10 Si bien son varios los autores que reflejaron este cambio en sus trabajos, las direcciones en las que apuntan éstos no serán siempre homogéneas, más bien, lo común será que las posiciones disientan entre sí. Por eso para algunos puede resultar impropio hablar de una EMDN, esto ya que rigurosamente hablando, nunca se habría formado una escuela propiamente tal. Lo que sí precisan algunos autores, es que lo que se puede indicar, son diferentes tendencias que se albergan dentro del conjunto del naturalismo moderno (F. Puy, Lecciones de derecho 
En general se puede decir que las tesis características que desarrollará la EMDN serán fundamentalmente tres:

- El individuo es el fundamento del derecho: para el iusnaturalismo moderno, no existe, en el plano real, nada más que los individuos, siendo la especie y el género, o puros conceptos, o simples etiquetas (nominalismo). La especie humana, en consecuencia, no tiene ninguna realidad como esencia universal, pues en la realidad no existen más que los individuos aislados ${ }^{11}$.

- El estado de naturaleza y el estado de sociabilidad son distintos: el hombre en estado natural no fue un ser que vivió en sociedad, sino "un individuo absoluto en estado asocial, soberano de sí, titular de todo posible derecho. El estado civil o estado de sociedad provino del hecho de que los hombres se unieron voluntariamente en la sociedad política"12.

- El origen del derecho está en un contrato social, real o hipotético: para la EMDN las instituciones sociales ya no son dadas naturalmente, sino que son dadas por acuerdos concertados entre individuos. Debido a la naturaleza asocial y ajurídica del estado natural es que los hombres pueden estimar conveniente realizar contratos o pactos.

Son estos principios y nociones mencionadas, los pilares epistémicos de donde los autores contractuales proyectaran sus teorías.

\subsubsection{Los contractualismos}

Los contractualismos serán las primeras propuestas teóricas de ordenamiento estatal totalmente laicas. Estas aparecen con toda claridad y elaboración en la época moderna, aunque con notables diferencias entre ellas. Entre los diversos autores que desarrollan propuestas contractuales, tres serán los que históricamente destacarán. Hablamos de Hobbes, Locke y Rousseau, los celebres "autores contractuales clásicos". La mayoría de la literatura especializada considera que estos autores articulan sus propuestas contractuales exclusivamente desde el racionalismo-deductivo ${ }^{13}$, o sea, desde el ejercicio mental lógico que prescinde de la validación empírica. Sin embargo, consideramos que esta estimación es errónea, y que los contractualismos sí manifiestan una cierta base empírica en la cual sostienen sus planteamientos. Esta base empírica la daría fundamentalmente la referencia a América. En las siguientes secciones desarrollaremos en mayor detalle esta afirmación.

natural, Tomo I, Santiago de Compostela, Porto y Cía. editores, 1970, pp. 197-204). Por estimaciones metodológico-prácticas, nosotros no diferenciaremos estas tendencias en detalle ya que no es el objetivo del artículo hilar fino en este aspecto, por ello mantendremos el uso del término EMDN que sintetiza estas tendencias.

11 J. Hervada, op. cit., p. 85.

12 Ibidem, p. 85.

13 E. Rommel, Derecho natural: Historia-doctrina, México D.F., Editorial Jus, 1950; F. Puy, Lecciones de derecho natural (Tomo I), Santiago de Compostela, Porto y Cía. editores, 1970. 


\section{Visiones de América y diferencias en los contractualismos}

\subsection{El contractualismo de Hobbes}

Un punto en el que la mayoría de los investigadores de las ideas políticas concuerdan ${ }^{14}$, es que la filosofía política de Hobbes, tal como lo dice Leo Strauss: "Constituye el primer intento peculiarmente moderno de dar una respuesta coherente y exhaustiva a la pregunta por la vida justa del hombre, que es al mismo tiempo la pregunta por el orden justo de la sociedad" ${ }^{15}$. Hobbes, en este sentido, fue el primero en efectuar una ruptura general con la tradición política anterior a él, fuertemente basada en el aristotelismo y la escolástica, y fue pionero también en experimentar la necesidad de una nuova scienza del hombre y del Estado.

En las obras De Cive (1642) y el Leviathan (1651), el inglés aduce argumentos que justificarían la creación del hombre artificial - Estado- . Estos argumentos se originarían a consecuencia del análisis que hace Hobbes de las "condiciones objetivas" que la humanidad evidencia en su estado natural - condiciones independientes de su voluntad-. Entre estas condiciones objetivas, la principal es la igualdad de hecho. En tanto somos iguales por naturaleza, los hombres son capaces de procurar salvaguardar su integridad. El derecho a la auto-conservación se da de una manera homogénea en todo ser viviente; aparentemente esta condición no sería negativa en sí misma, sin embargo, cuando los recursos son escasos se suscita un estado de competencia que amenaza la supervivencia de todos. En esos momentos, y a condición de salvaguardar el derecho de auto-conservación de cada uno, es donde para Hobbes el conflicto despiadado decae en lucha violenta. La situación "se ve agravada por el hecho de que los seres a los que la naturaleza ha puesto en tal dificultad, están dominados por las pasiones que les predisponen más para la insociabilidad que para la sociabilidad"16. Así en el estado natural hobbesiano, los hombres se encuentran en un ambiente de violencia endémica interminable de "guerra de todos contra todos". La razón de que el estado natural sea de este modo se explica para el nacido en Westport por dos razones: por el hecho de que en este nivel barbárico no hay aún normas intersubjetivamente válidas; $y$, por otro lado, porque los hombres obran por motivos egoístas - se guían por sus deseos primarios de supervivencia, deseos que son saciados mediante la depredación, el pillaje y actos semejantes-. En este sentido, el estado de naturaleza para Hobbes correspondería a un nivel pre-social que resulta ruinoso para todos; esto dado a que en este estado primigenio no hay un poder soberano que imponga orden y logre evitar la violencia entre los hombres. Así resume este perjudicial estado el inglés: "No había artes, ni letras, ni sociedad alguna. Y, lo que es peor de todo, imperaban un continuo terror y el peligro de padecer muerte violenta. Y la vida del hombre era solitaria, miserable, sucia, embrutecida y corta" 17 . Esta visión antropológica negativa de Hobbes proyecta un dilema con consecuencias asociadas: la opción de gobierno que elige el ser humano determina su porvenir

14 N. Bobbio, Thomas Hobbes, México, FCE, 1986, pp. 34-67; G. Sabine, Historia de la teoría política, México, FCE, 2009, pp. 354-367; C. Schmitt, El Leviatán en la teoría del estado de Thomas Hobbes, Buenos aires, Alianza editorial, 2002, pp. 15-28.

15 L. Strauss, La filosofia politica de Thomas Hobbes, Buenos Aires, FCE, 2006, p. 21.

16 N. Bobbio, op. cit., p. 44.

17 T. Hobbes, Leviatán, México D.F., FCE, 2006, p. 114. 
como existencia. Para Hobbes, los hombres tienen que optar entre dos disposiciones sociales organizativas: por un lado está la "anarquía", que se da de manera espontánea o natural - en esta forma se perpetúa la violencia endémica y la guerra de todos contra todos-; por otro lado está el "absolutismo", el cual se dispone de manera artificial — esta forma salvaguarda a los individuos de la guerra endémica- Para Hobbes la elección es clara, debe optar por el artificio Estado-absolutista. Esto, porque la anarquía, que en ocasiones el inglés la tipifica con la figura mitológica hebrea del Behemoth ${ }^{18}$, nos resulta ruinosa y desventajosa para todos y amenaza la integridad vital de los individuos, por lo que es más conveniente renunciar al derecho de autogobernarse y acordar un pacto con un poder absoluto, el cual provea de normas generales a los individuos en sus relaciones mutuas - para Hobbes la justicia no es sino una forma de preservar y promover la propia conveniencia y la vida ${ }^{19}$ - En resumen, Hobbes plantea un problema de conducta práctica: la humanidad se enfrenta a un mundo en el que el justo y el inocente se ven expuestos a la destrucción si no actúan con energía implacable para remediarlo.

\subsubsection{América como el punto de proyección del contractualismo de Hobbes}

Considerando lo novedosas que son las hipótesis de Hobbes para su época, cabría hacerse diferentes preguntas acerca de los conceptos que presenta para articular su contractualismo, empezando, por ejemplo: ¿De dónde saca estas ideas Hobbes acerca del estado de naturaleza? ¿Acaso lo imaginó todo, u observó alguna evidencia concreta que advirtiera esta forma de estado?

Como ya se ha señalado, Hobbes intenta establecer una teoría secular de la soberanía. En este contexto, el inglés es consciente, que para que su propuesta tenga aquel carácter laico, debe de cimentarse sobre una base epistémica diferente a la de la teoría de la delegación divina del poder propias de la tradición aristotélico-tomista del derecho natural - teoría del poder aún con mucha vigencia en tiempos de Hobbes- . Precisamente por esto, tratar de darle a su propuesta una perspectiva epistémica diferente de la delegativa-divina, que la impronta de América tendrá un valor central en el esquema hobbesiano. Para el inglés, la referencia al nuevo mundo no es casual, América es un "caso de observación" del Estado de naturaleza, un ejemplo concreto que sostendrá a los hipotéticos de forma empírica. Hay que recordar que Hobbes estaba fuertemente influido por la revolución científica encabezada por Bacon, Galileo y Descartes, personajes los cuales conoció. La ciencia sobre "los cuerpos y movimientos" parecía resolver toda la complejidad de los fenómenos físicos a

18 Es interesante percatar que en el libro el Behemoth (1681) de Hobbes, se trate de representar la catástrofe del sin gobierno y la revolución con la figura bestial homónima a la obra - figura que es citada originariamente en el libro de Job-. Carl Schmitt (op. cit., pp. 20-24) argüirá, que el Behemoth es una representación metafórica que complementa al Leviatán — otra figura mitológica hebrea que también aparece en Job-. Para Hobbes el Leviatán representa al saber técnico-político; es una máquina que controla las interminables pasiones humanas, máquina sin la cual no es posible ningún orden social ni la paz. En la lectura schmittiana, la construcción humana del Leviatán constituye precisamente el modo de escapar a la amenaza encarnada de la guerra de todos contra todos, una creación monumental que se enfrenta también contra la monstruosidad de la revolución y la anarquía —el Behemoth-.

19 La única forma de lograr un Estado de Sociedad es mediante el imperio de la ley, esto, ya que la ley limita el accionar del hombre que tiende al egoísmo y la satisfacción personal. Solo mediante la "justicia" se puede instaurar un régimen de paz y orden, lo que permite la existencia de la sociedad. 
través de axiomas y fórmulas que podían ser demostradas empíricamente ${ }^{20}$ ¿Podía entonces el modelo epistemológico de las ciencias formales ser adaptado para resolver el puzzle de la naturaleza humana? ¿Se podía a través de unos axiomas fundar una nueva teoría política? Hobbes cree que sí, solo había que comprender, mediante la vía racional-analítica, como era el movimiento de los "cuerpos naturales" —-hombres_-, para explicar la existencia de los "cuerpos artificiales" —Estado ${ }^{21}$ —. Es por esto la importancia de la inclusión de América en la teoría contractualista de Hobbes, ya que en este continente se evidenciaría de forma pura el comportamiento bestial de la etapa natural pre-social, dando, por lo tanto, sustento concreto a lo hipotetizado. Así lo dice el inglés en su libro De Cive:

Esta guerra, naturalmente, debería durar eternamente, sin ninguna esperanza; a causa de la igualdad de los combatientes no es posible una victoria que le dé término: los vencedores siempre se verán envueltos en nuevos peligros. (...) Tenemos un ejemplo sobre lo que digo, en este siglo, en los americanos. En las edades pasadas hemos tenido naciones que hoy día son civilizadas y florecientes, pero que fueron despobladas, salvajes y privadas de las ventajas que aportan la paz y la sociedad a quienes las cultivan. Aquellos que estiman que debemos permanecer en ese estado, en que todas las cosas son de todos, se contradicen a sí mismos: cada cual desea naturalmente aquello que es un bien para sí, y nadie puede estimar que esta guerra de todos contra todos, constitutiva del estado de naturaleza, sea algo bueno. Por esta razón, movidos por un temor mutuo, nosotros deseamos salir de este incómodo estado y buscamos la sociedad ${ }^{22}$.

En la concepción del autor inglés, América sirve como la referencia concreta de su teoría contractual, es el paradigma por antonomasia de la guerra civil permanente. Al igual que en su obra De Cive, en el Leviatán, reafirmará esta concepción negativa del amerindio:

Acaso puede pensarse que nunca existió un tiempo o condición en que se diera una guerra semejante, y, en efecto, yo creo que nunca ocurrió generalmente así, en el mundo entero; pero existen varios lugares donde viven ahora de ese modo. Los pueblos salvajes en varias comarcas de América, si se exceptúa el régimen de pequeñas familias cuya concordia depende de la concupiscencia natural, carecen de gobierno en absoluto, y viven actualmente en ese estado bestial al que me he referido ${ }^{23}$.

Hobbes toma las noticias y relatos de los viajeros que volvían de remotos países —aún por “civilizar”_, relatos que por lo demás eran divergentes entre sí, y condensa estas experiencias bajo una sola interpretación, funcional a su propuesta de la vida pre-social. Hablar entonces del estado de naturaleza, sería remitirse a una condición de guerra e inseguridad permanente ¿Cuál será entonces la solución para salir de esta condición? El mismo inglés la señala: una autoridad fuerte, como la del

\footnotetext{
O. Godoy, "Selección de escritos políticos de Thomas Hobbes", Estudios Públicos, 23, 1986, pp. 1-38.

D. Thomson, op. cit., pp. 51-66.

T. Hobbes, De Cive. Madrid, Alianza editorial, 2000, p. 63.

T. Hobbes, Leviatán. México D.F., FCE, 2006, pp. 103-104.
} 
monarca absoluto. Para Hobbes, el estado de naturaleza no es un mito semi-histórico que se haya de relegar a un remoto pasado, es más bien un abismo siempre presente, que bordeamos a diario y que olvidamos con imprudente alegría.

Desde la perspectiva mecanicista de Hobbes se podría decir que América representa el Estado de Naturaleza (X), en el "nuevo mundo" se evidencia la "guerra de todos contra todos", pero no se vislumbra el Estado de Sociedad (Y). Esto se debería a que América no ha llevado a cabo los procesos que la conduzcan a ese estado. En primer lugar, en el continente americano no hay evidencia de un pacto (n1) que ayude a superar el estado de guerra constante de las "comarcas americanas" entre sí; y como no hay pacto - delegación de soberanía-, tampoco hay registro del tipo de instauración de Estado que se dé, con sus leyes y mecanismos de funcionamiento. En este contexto, como $\mathrm{n} 1$ está ausente en la secuencia causal que nos lleve a $\mathrm{Y}$, la condición de América solo se restringiría a $\mathrm{X}$, en el nuevo mundo no hay un isomorfismo entre la teoría y la evidencia para Y, pero sí en Europa que ha dejado atrás el "salvajismo" de la etapa pre-social.

En la Figura 1 se sintetiza el modelo mecanicista deducido por Hobbes

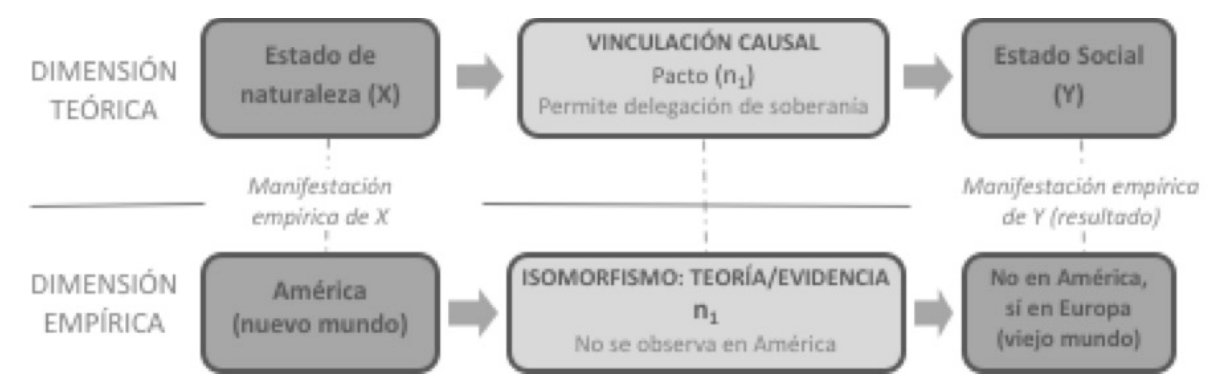

Figura 1. Modelo mecanicista de Hobbes para explicar el surgimiento de los Estados Sociales de forma secular. Elaboración propia

En resumen, Hobbes hace uso referencial de América como la evidencia material del estado natural, aquello le da una dimensión concreta a su teoría secular del poder. El nuevo mundo será para el inglés, la proposición "evidente por sí misma" de su sistema hipotético-deductivo: la demostración empírica — como caso de observación - de la existencia del estado pre-social ruinoso para todos. Es así que la referencia a América le conferirá a la teoría de Hobbes, una diferente base epistémica de sustento, esta ya no se constituiría sobre una matriz "religiosa" — como en el caso de la teoría de la delegación divina - sino sobre una perspectiva "racional-científica".

\subsection{El contractualismo de Locke}

La concepción antropológica pesimista de Hobbes y el modelo político legitimado por ésta eran incompatibles con las transformaciones políticas de la Europa del siglo XVII — Hobbes era simpatizante del absolutismo monárquico- . Sin embargo, la estructura de su razonamiento - se sale del estado de naturaleza mediante un pacto social el cual permite un estado de sociedad - resultó ser muy flexible para adecuarse a diversas formas de gobierno. Un ejemplo de aquello es la concepción contractualista asumida por John Locke, manifestada en forma clara en su obra: Dos 
tratados sobre el gobierno civil (1689), donde mantuvo el esquema original básico de tres ejes, para adaptarlo a las necesidades del Estado liberal.

En el estado de naturaleza del filósofo y médico inglés, los individuos están menos determinados o aislados psicológicamente que en Hobbes: son seres libres, pacíficos y con derecho a la autotutela. Locke no prejuzga la maldad o bondad del ser humano, se limita a afirmar que antes de la aparición del Estado - es decir, del pacto y del Estado social - los seres humanos gozan de ciertos derechos naturales: vida, libertad y propiedad, que se pueden equilibrar bajo delgados límites de la ley de naturaleza. Así lo señala el inglés:

Para entender el poder político correctamente, y para deducirlo de lo que fue su origen, hemos de considerar cuál es el estado en que los hombres se hallan por naturaleza. Y éste un estado de perfecta libertad para que cada uno ordene sus acciones y disponga de posesiones y personas como juzgue oportuno, dentro de los límites de la ley de naturaleza, sin pedir permiso ni depender de la voluntad de ningún otro hombre (...) Es también un estado de igualdad, en el que todo poder y jurisdicción son recíprocos, y donde nadie los disfruta en mayor medida que los demás ${ }^{24}$.

Fundamentalmente hasta aquí, pareciera que el estado de naturaleza Lockeano es más una panacea que un hábitat de lobos. Sin embargo, el nacido en Wrington añade que este estado de equilibrio se rompe en ocasiones, por lo que se podría tender a la guerra, esto, porque en la etapa pre-social regiría para cada uno su derecho de auto-preservación, y por lo mismo, al carecer el estado natural de una autoridad fuerte que ordene y regule lo social, eventualmente los derechos que cada cual reclama a su favor pueden entrar en conflicto, imperando el de aquellas voluntades más fuertes por sobre el de las más débiles, imposibilitando, por tanto, la protección de los derechos naturales primordiales de forma equitativa, por lo que lo más conveniente sería: crear un Estado que cuente con un poder legislativo supremo, diferente al ejecutivo, representativo de la comunidad y cuyo deber sea garantizar la vida, la libertad y el resguardo de la propiedad conforme a la ley que aplica a un poder ejecutivo independiente ${ }^{25}$.

A esta extraña doctrina - es decir, a la doctrina de que en el estado de naturaleza cada hombre tiene el poder de hacer que se ejecute la ley natural— se le opondrá, sin duda, la objeción de que no es razonable que los hombres sean jueces de su propia causa; (...) su pasión y su deseo de venganza los llevarán demasiado lejos al castigar a otros, de lo cual sólo podrá seguirse la confusión y el desorden; y que, por lo tanto, es Dios el que ha puesto en el mundo los gobiernos, a fin de poner

\footnotetext{
J. Locke, Segundo Tratado sobre el Gobierno Civil. Madrid, Tecnos, 2006, p. 10.

25 Además de la diferencia que le da Locke a la perspectiva de su Estado de Naturaleza a la de Hobbes, también difiere con el autor del Leviatán, que en el pacto que se hace para garantizar el orden y la paz, los individuos no necesariamente deben ceder sus derechos a un soberano - poder ejecutivo - como lo señalaba Hobbes, sino que también pueden hacerlo a un grupo de soberanos — poder legislativo- - y esto, teniendo en cuenta que tal cesión no es perpetua ni irrevocable, también hay "derecho a la rebelión” si el soberano no cumple con lo pactado; esto a contrapelo con lo que plantea Hobbes que señala que el pacto no lo pueden romper los individuos sino que sólo eventualmente lo podría hacer el soberano al cual se le delegó toda la autoridad. D. Thomson, op. cit., pp. 67-80; B. Arneill, John Locke and America: The defence of english colonialism, New York, Oxford University Press, 1996, pp. 21-45.
} 
coto a la parcialidad y violencia de los hombres. Concedo sin reservas que el gobierno civil ha de ser el remedio contra las inconveniencias que lleva consigo el estado de naturaleza ${ }^{26}$.

Locke no da precisiones sobre el origen de las "leyes de naturaleza". Si bien insiste en que son compulsivas, pues han sido impuestas por dios, estas también son racionales; esto, porque podemos reconocerlas intelectivamente, y por lo tanto, estas leyes son universales y absolutas ${ }^{27}$.

\subsubsection{América como el punto de proyección del contractualismo de Locke}

Hasta aquí, al igual que con lo planteado por Hobbes, surgen similares dudas con las afirmaciones de Locke acerca de la necesidad de un gobierno civil. Cabe preguntarse, por ejemplo: ¿de dónde saca Locke esta idea de estado de naturaleza? Y el análisis a la obra del médico inglés demuestra que la respuesta es la misma que con Hobbes: de América. Al igual que el autor del Leviatán, Locke mira al nuevo continente como el nivel pre-social, pero a diferencia de su coterráneo, para él, los individuos americanos a pesar de que están en una condición primitiva, pueden llegar, por medio de la experiencia, a comprender lo que es el bien y el mal — son "tabulas rasas" que se moldean según los estímulos a los que son expuestos-, y por lo tanto, no están tan determinados psicológicamente. Así lo señala Locke:

¿Dónde pueden encontrarse hombres que existan en un estado natural así? ¿Existieron alguna vez? (...) pues no todo pacto pone fin al estado de naturaleza entre los hombres, sino solamente el que los hace establecer el acuerdo mutuo de entrar en una comunidad y formar un cuerpo político. Hay otras promesas y convenios que los hombres pueden hacer entre sí, sin dejar por ello el estado de naturaleza. Las promesas y compromisos de trueque, etc., entre los dos hombres en la isla desierta mencionados por Garcilaso de la Vega en su Historia del Perú, o entre un suizo y un indio en las selvas de América, los obligan a ambos, aunque siguen hallándose en un estado de naturaleza el uno con respecto al otro (...) Permanecen hasta que, por su propio consentimiento, se hacen a sí mismos miembros de alguna sociedad política ${ }^{28}$.

La comunidad pre-política de Locke es en esencia una versión benevolente de su propia sociedad del siglo XVII, pero con excepción de que aún esa comunidad no ha llevado a cabo el pacto que los conforme como sociedad civil. Sin embargo, a diferencia de Hobbes, que ve a los americanos en un estado de bestialidad, Locke los ve más como en un estado donde no hay un sistema moral tan consolidado, y se vive en base a una ética deductiva basada en las leyes naturales evidentes por sí mismas.

Y si aceptamos la palabra de José Acosta ${ }^{29}$, lo que este historiador nos dice es que en muchas partes de América no había gobierno en absoluto. "Hay grandes y evi-

\footnotetext{
J. Locke, Segundo Tratado sobre el Gobierno Civil. Madrid, Tecnos, 2006, p. 18.

C. Miranda, "Selección de escritos de John Locke", Estudios Públicos, 44, 1991, pp. 1-38.

J. Locke, op. cit., pp. 19-20.

Historiador y misionero español, miembro de la Compañía de Jesús.
} 
dentes indicios", nos dice refiriéndose a los nativos del Perú, "de que estos hombres carecieron por mucho tiempo de reyes y de Estados; y que vivieron en hordas, como hacen en el día de hoy los Cheriquanas en Florida, los indios del Brasil y muchos otros pueblos que no tienen reyes fijos sino que, cuando la ocasión se presenta, ya sea en tiempo de paz o en tiempo de guerra, escogen a sus capitanes según les place" (...) Por consiguiente, todas sus sociedades políticas tuvieron su origen en una unión voluntaria y un acuerdo mutuo (...) aquellos pueblos de América que estaban fuera del alcance de las conquistas militares y de la dominación de los grandes imperios de Perú y de México disfrutaron de su propia libertad natural ${ }^{30}$.

América en este caso viviría, sobre todo sus más grandes civilizaciones, en el ámbito de los preceptos ambiguos de la ley natural, que están en camino transitorio a convertirse en leyes del Derecho positivo más claras y aplicables. Por eso en un principio los individuos no constituyen un Estado, sino que acuerdan formar una sociedad contractual. Esta sociedad contractual es muy similar en su dinámica a las entidades comerciales anónimas en las que participan libremente los individuos para beneficiarse unos a otros ${ }^{31}$. Para Locke el continente americano será el ejemplo concreto de una sociedad-liberal primitiva, así lo sostendrá:

Ésta fue, en un principio, la situación en América, mucho más de lo que es ahora; pues en ninguna parte se conocía allí cosa parecida al dinero. Mas tan pronto como un hombre descubre que hay algo que tiene el uso y el valor del dinero en sus relaciones con sus vecinos, veremos que ese hombre empieza a aumentar sus posesiones ${ }^{32}$.

En Locke, América vive una transición paulatina hacia el Estado; sin cambios traumáticos se comenzará a establecer un derecho de propiedad vinculante, que es mediado por la posesión legítima de la tierra en criterio de los diferentes grados de laboriosidad - la tierra es de quien la trabaja ${ }^{33}$ - . En la medida que el dinero, como depósito de valor y bien de cambio, empieza a asentar un sistema monetario en el continente americano - reemplazando al sistema de trocado y semi-monetario anterior-, la dinámica económica cambiará pasando del simple autoabastecimiento al comercio de grandes escalas ${ }^{34}$; sin embargo, este proceso de desarrollo comercial, arguye Locke, no será rápido sino pausado, y se lograría consolidar en el tiempo más gracias a la intervención colonial europea que por el propio accionar amerindio.

Por eso vemos que los reyes de los indios de América (que continúan siendo una réplica de los que fueron los tiempos primitivos en Asia y en Europa —una época

\footnotetext{
Ibidem, pp. 102-106.

B. Arneill, op. cit., pp. 88-117.

J. Locke, op. cit., p.54.

33 Locke estaba muy inmerso en el desarrollo de la política colonial inglesa, esto en un momento en que existía una fuerte oposición a las actividades de Inglaterra en Estados Unidos — durante el siglo XVII surgieron cuestionamientos sobre el derecho de Inglaterra a apropiarse de la tierra ya ocupada por otra gente- - En este contexto, el médico inglés intentó defender los derechos colonizadores de Inglaterra en Estados Unidos; señalando que antes que llegasen éstos, la potencial riqueza de la tierra se perdía, ya que no se trabajaba sobre la misma, y que los colonizadores al trabajarla generaban patrimonio que extrapolaba en desarrollo y progreso social, el cual no hubiese existido sin el accionar colono (B. Arneill, op. cit, pp. 88-117).

34 B. Arneill, op. cit., pp. 132-167; C. Miranda, “Antología política de Rousseau”, Estudios Públicos, 65, 1997, pp. 321-377.
} 
en la que los habitantes de cada país eran muy escasos y la falta de gente y de dinero eliminaba toda tentación de que los hombres aumentarán sus posesiones de terreno o disputaran para extender la amplitud de sus dominios), se limitan a ser generales de sus ejércitos ${ }^{35}$.

En resumen, América en la concepción Lockeana, a diferencia de la visión negativa de Hobbes, es una sociedad amoral que se encuentra en un proceso de construcción y maduración. Independientemente de la disímil ontología con que Locke presenta a su estado de naturaleza con respecto al de Hobbes, en último término, el nacido en Wrington, al igual que el autor del Leviatán, termina haciendo un uso referencial de América para sustentar empíricamente el edificio de su propuesta contractual.

\subsection{El contractualismo de Rousseau}

Rousseau al igual que Hobbes y Locke, parte del hipotético estado de naturaleza seguido por una explicación contractual sobre el consentimiento y la obligación, y las inevitables conclusiones sobre la necesidad de un Estado, sin embargo, sólo hasta ahí llegan las similitudes. Señala en su célebre Discurso sobre la desigualdad (1749), que los seres humanos no responden a las descripciones de Hobbes, que no eran sujetos perfectamente formados con una personalidad fija, más bien los hombres son mutables y moldeables. Para el ginebrino, las diferentes formas de existencia que afrontan los individuos humanos hacen que estos evolucionen y se moldeen de acuerdo con el tipo de civilización en la que están insertos. Los hombres han creado Estados políticos opresivos e injustos, y estos han generado los individuos viles y codiciosos de los que hablaba Hobbes. Pero para Rousseau, la mayoría de las personas son ajenas a las instituciones que ellas mismas crearon. Los hombres y las mujeres pre-sociales que viven en un estado de naturaleza no son seres malos o bestiales como en Hobbes o potenciales aristócratas terratenientes como en Locke, sino más bien son buenos, y se convierten en corruptos con la aparición de la sociedad y la invención de la agricultura, la cual trajo consigo el peor de los males: la propiedad. Es desde ahí que se introduce la desigualdad económica, la corrupción y el egoísmo ${ }^{36}$. Para Rousseau el surgimiento del Estado moderno se da según la siguiente causalidad: unos pocos privilegiados crean contratos políticos y sociales, estos contratos, presumiblemente hechos para mantener la paz y la seguridad, terminan por salvaguardar intereses de una minoría a la cual se le asegura la protección de sus derechos de propiedad mediante la coacción estatal. Así lo resume el autor suizo:

El primer hombre que, habiendo cercado con vallas una porción de terreno, reflexionó y se dijo: "esto es mío", y halló gente tan simple como para creerle, ése fue el verdadero fundador de la sociedad civil. ¡De cuántos crímenes, guerras y asesinatos, de cuantos horrores y desventuras no podría haber librado alguien a la humanidad arrancando aquellas estacas o rellenando aquella zanja y gritando a sus semejantes: "guardaos de prestar oídos a ese impostor: será vuestra perdición

35 J. Locke, op. cit., p. 54.

36 C. Miranda, op. cit., pp. 321-377. 
cuando olvidéis alguna vez que los frutos de la tierra nos pertenece a todos y que la tierra misma no es de nadie en particular"! ${ }^{37}$

\subsubsection{América como el punto de proyección del contractualismo de Rousseau}

A diferencia de los hombres "civilizados" ya corrompidos por la sociedad, los seres humanos en estado natural del continente americano vivirían en una suerte de inocencia originaria, para estos hombres no hay pasado, por lo que tampoco hay remordimientos de injusticia, y acerca del futuro no piensan, sólo viven el presente. Su estado de naturaleza se caracteriza por la libertad, la igualdad, la felicidad y la bondad. Y si bien la mirada de Rousseau del estado natural es similar en lo arbitraria a la de Hobbes y Locke, la del ginebrino posee un carácter antropológico más positivo.

Es, pues, un hecho indiscutible que el mismo amor como todas las otras pasiones, no ha adquirido en la sociedad ese ardor impetuoso que lo hace tan a menudo funesto a los hombres, siendo tanto más ridículo representar a los salvajes como si se estuviesen matando sin cesar para saciar su brutalidad, cuanto que esta opinión es absolutamente contraria a la experiencia, pues los caribes, que es hasta ahora, de los pueblos existentes, el que menos se ha alejado del estado natural, son precisamente los más sosegados en sus amores y los menos sujetos a los $\operatorname{celos}^{38}$.

Para Rousseau los nativos americanos son individuos inofensivos, seres aislados e ignorantes de la ley natural, los cuales se guían en base a acciones reflejas e impulsos; no tienen entre ellos ninguna especie de relación moral, ni deberes conocidos, no son ni buenos ni malos, no tienen ni vicios ni virtudes; $y$ a pesar de las carencias formativas, instintivamente evitan dañarse unos a otros. Así Rousseau los personificará:

Sus almas, que nada agitan, se entregan al sentimiento único de su existencia actual, sin idea alguna sobre el porvenir, por cercano que pueda estar, y sus proyectos, limitados como sus miras, apenas se extienden hasta el fin de la jornada. Tal es aún el grado de previsión del Caribe: vende por la mañana su lecho de algodón y vuelve llorando al atardecer para recuperarlo, por no haber previsto que lo necesitaría para la noche cercana ${ }^{39}$.

Nuevamente la impronta de América se visualiza como el espacio de apoyo a las propuestas filosóficas contractualistas, y en Rousseau, es aún más clara esa vinculación, llegando muchas veces el ginebrino a hacer paralelos directos entre el mundo del "hombre salvaje" —el americano-y el "civilizado" —el europeo-.

El hombre salvaje y el hombre civilizado difieren de tal modo por el corazón y por las inclinaciones, que aquello que constituye la felicidad suprema de uno reduciría al otro a la desesperación. El primero sólo disfruta del reposo y de la libertad (...) El ciudadano, por el contrario, siempre activo, suda, se agita, se atormenta ince-

\footnotetext{
J.J. Rousseau, op. cit., p. 57.

J.J. Rousseau, Discurso sobre el origen de la desigualdad, Toronto, Ediciones elAleph.com, 1999, p. 52.

Ibidem, p. 36.
} 
santemente buscando ocupaciones todavía más laboriosas; trabaja hasta la muerte, y aun corre a ella para poder vivir, o renuncia a la vida para adquirir la inmortalidad; adula a los poderosos, a quienes odia, y a los ricos, a quienes desprecia, y nada excusa para conseguir el honor de servirlos (...) ¡Qué espectáculo para un Caribe los trabajos penosos y envidiados de un ministro europeo $!^{40}$.

Rousseau rescata al amerindio como arquetipo de incorruptibilidad, lo hace con la intención de dar algunas recetas para salvarse de la corrupción de la sociedad moderna. En su novela de ribetes filosóficos Julia, o la nueva Eloísa (1761) y en su obra El Emilio, o De la educación (1762), dejara entrever que mediante la educación y el acercamiento temprano y en solitario a ese estado natural primigenio, la carga negativa de la sociedad se atenuaría. Para el suizo, América y la forma de vida de los caribes venezolanos serían uno de los ejemplos a replicar para limpiarse de los vicios de la sociedad; por lo que en una segunda etapa, ya de integración a la vida pública, alrededor de los 15 años, las pretensiones de vida serían menos egoístas y más nobles ${ }^{41}$. Los seres humanos, en este sentido, deben tratar de conciliar el amor de sí con el bien de la comunidad, evitar la excesiva adhesión hacia uno mismo que produce la vanidad — factor espiritual — y la propiedad privada — factor material — ya que estos son la "raíz de la desigualdad".

Según Rousseau, se puede fundar un nuevo pacto social con la educación, donde las virtudes del hombre natural se proyecten para hacer frente a la corrupción y establecer un gobierno de la voluntad general más justo e igualitario. Un "consenso" en el que todos participen siendo legisladores y súbditos a la vez ${ }^{42}$.

\section{Conclusiones}

La problemática de apropiar a América en el pensamiento occidental dio como resultado un desarrollo analítico y conceptual que incidirá en las formas de entender la política y el poder. En este contexto, términos como estado de naturaleza, pacto o contrato social y estado social serán reelaborados en su significación para ser dispuestos en la conformación de la primera teoría política que justifica la soberanía de una forma secular: el contractualismo. Con Hobbes, que es el primero en proponer un modelo contractual plenamente desarrollado, y posteriormente con otros pensadores contractuales como lo son Locke o Rousseau, la soberanía política ya no procedería por delegación divina — derecho natural clásico - sino que es traspasada por un pacto entre los hombres hacia una instancia terrenal. La instancia en estos autores diferirá: para Hobbes, lo recomendable será que la delegación soberana sea a un monarca absoluto; para Locke, a una monarquía parlamentaria; y para Rousseau, a la voluntad general. Dios en este sentido "ya no funciona como fuente última de garantía del orden, el orden no está dado, debe ser creado por la voluntad y el artificio humano ${ }^{43}$ ".

\footnotetext{
I0 $\quad$ Ibidem, p. 88.

41 J.J. Rousseau, Julia, o la nueva Heloisa, Barcelona, Imprenta de Oliva, 1836, pp. 1 ss.; J.J. Rousseau, Emilio, o, de la educación, México D.F., Porrúa, 1978, pp. 6 ss.

42 C. Miranda, op. cit., pp. 321-377.

43 M. Sirczuk, "Teología política y modernidad. Carl Schmitt y el pensamiento político posfundacional", en Res publica. Revista de Filosofía Política 25, 2011, pp. 199-213, aquí p. 206.
} 
América será una pieza central en el esquema contractual, principalmente, porque es usada por los autores como el "caso de observación" que confirma los hipotéticos y cubre a esos postulados de materialidad; el nuevo mundo es en este sentido, un ejemplo real del estado de naturaleza, de aquélla caótica condición pre-social de la cual se hizo necesario salir mediante la creación de instituciones.

El ejercicio de sustentar lo planteado en una forma empírica mediante la demostración material —enfoque científico-, permite a Hobbes, Locke y Rousseau, explicar el surgimiento de los Estados, sin recurrir a premisas metafísicas de carácter sobrenatural — desde lo sensible se articula la teoría y esta encuentra en la misma dimensión sensible su validez y justificación-. En este contexto, América será de central importancia, esto, porque se erigirá como la referencia concreta con la que se sustenta la teoría. Sin el referente, lo planteado por Hobbes, Locke y Rousseau no sería más que un modelo teórico sin contenido sustancial, una simple construcción especulativa articulada desde la razón.

Por último, cabe también señalar, que los autores contractuales, al representar a América como el estado natural, no sólo sitúan a la misma en un esquema teórico que busca explicar secularmente la naturaleza social y su desarrollo, sino que también la ubican en un "relato político", relato en el que se representa al nuevo mundo como inmaduro e inferior. Y como América es inmadura e inferior, es lógico observar en ella: a la violencia incontrolada (Hobbes); a un sistema moral no consolidado (Locke); y a la ingenuidad e inocencia (Rousseau). Esto en contraposición de Europa que en la discursiva se muestra como un "viejo mundo", más civilizado y maduro, y, por lo tanto, menos infantil. Este "situar" a América en una condición menor con respecto a Europa - a excepción de Rousseau que tiene sus matices-, será relevante en términos del imaginario político ya que petrificará al Nuevo Mundo en una discursiva de inferioridad que en el tiempo se proyectara con distintos ropajes ${ }^{44}$.

44 Las formas en que el pensamiento europeo-occidental proyecta un "esencialismo de la inferioridad" en América y los países colonizados, es vista con mayor detalle por los autores de la llamada "teoría poscolonial" (G. Spivak, A Critique of Postcolonial Reason. Towards a History of the Vanishing Present, Cambridge, Harvard University Press, 1999, pp. 1 ss.; W. Mignolo, La idea de América Latina. La herida colonial y la opción decolonial, Barcelona, Gedisa, 2007, pp. 1 ss.; entre otros). 